\title{
Body fat measurements in children as predictors for the metabolic syndrome: focus on waist circumference
}

\author{
H. David McCarthy \\ Institute for Health Research \& Policy, London Metropolitan University, Holloway Road, London N7 8DB, UK
}

\begin{abstract}
The global epidemic of obesity in children will see a rise in the number of cases of metabolic syndrome, which is a clustering of CVD risk factors, including atherogenic levels of blood lipids, hyperinsulinaemia and raised blood pressure. Rather than excess general fatness (assessed by BMI), more specifically it is excess abdominal fatness, quantified by waist circumference measurement, which is a better measure of risk for these metabolic abnormalities in children of all ages. Insulin resistance, a consequence of excess visceral fat, is understood to be the driving force underpinning the metabolic syndrome. Consequently, assessment of abdominal fatness in children is proving to be more clinically useful. Waist circumference centile charts have now been developed for the UK and other paediatric populations to assist in this process. Furthermore, studies in the UK and elsewhere have shown that abdominal fatness has increased in infants, children and adolescents to a greater extent than overall fatness over the past 10-20 years, suggesting that obesity prevalence may be underestimated when based entirely on BMI. Additionally, ethnic differences in fat distribution have been demonstrated in children, with those from south Asian backgrounds having a greater abdominal distribution compared with Caucasian children and consequently having a much greater risk for type 2 diabetes. The information that can be provided by waist circumference measurement in children, as in adults, together with the recent changes in body fat distribution should provide the impetus for its measurement to be standardised and routinely taken in clinical and epidemiological settings.
\end{abstract}

Metabolic Syndrome: Abdominal obesity: Waist circumference: Children: Ethnicity

It is well established that there is an epidemic of overweight and obesity in both the adult and childhood populations within the UK and globally (Bundred et al. 2001; Chinn \& Rona, 2001; Lobstein et al. 2003). These data are based on BMI as the measure for overweight and obesity. The exact data are continually being updated, but those for England from the Health Survey for England (Sproston \& Primatesta, 2002) put the percentages for both overweight and obese categories at approximately 22 for boys and 28 for girls. The prevalence in the Republic of Ireland is not much different from that for the UK. Observers claim that this dramatic rise in obesity prevalence in children is fuelling a major public health crisis (Lobstein et al. 2004).

Obesity increases the risk for related morbidities, particularly the metabolic syndrome (MS; Must, 1996; Kopelman \& Albon, 1997), which is defined as a clustering of CVD risk factors, including impaired glucose tolerance, dyslipidaemia and hypertension. Obesity, especially abdominal obesity (in which lipid deposition in visceral adipose tissue is increased) is fundamental to the MS. Insulin resistance, a consequence of abdominal obesity, is understood to be the driving force of MS (Weiss \& Caprio, 2005). Across increasing body-weight categories there is a rising and significant trend for the metabolic variables associated with the MS, including plasma glucose and insulin concentrations, increasing triacylglycerol levels, decreasing HDL levels, increased impaired glucose tolerance test and increased systolic blood pressure ( $P$ for trend <0.001; Weiss et al. 2004). Consequently, it has been reported that the MS is one of the most pressing dietrelated public health issues to affect future generations, as risk for MS has been shown to originate early in life.

Most often in a clinical situation it will be the child's BMI that will initiate further examination for comorbidities. BMI represents the sum of fat-free mass and

\footnotetext{
Abbreviations: ALSPAC, Avon Longitudinal Study of Parents and Children; MS, metabolic syndrome; WC, waist circumference; WHtR, WC: height ratio. 
fat mass. BMI charts for clinical use in children have been available for some time (Cole et al. 1995, 2000; Dietz \& Bellizzi, 1999; National Center for Health Statistics, 2000). In relation to the use of BMI in children, it may well be that this type of measurement does not fully capture all those children who may be at risk for the MS. This situation is in part a result of its sensitivity and specificity. Whilst BMI is able to correctly identify the fattest children in a sample (high specificity, low false positive rate), because of its low sensitivity (moderate-high false negative rate) it can misclassify large numbers of children with a high body fat content (Reilly et al. 2000). Furthermore, BMI is unable to distinguish between gains in fat-free mass and gains in fat mass. In an epidemiological context, as BMI is used to monitor trends in overweight and obesity in children, its known limitations can therefore be particularly problematic for public health applications such as surveillance of obesity (Ellis et al. 1999; Moreno et al. 2000).

Another major drawback with BMI is that its measurement gives no indication of body fat distribution. It has been known for some time that a central distribution of body fat, particularly an excess accumulation of fat intraabdominally rather than a more peripheral distribution, carries a higher risk for obesity-related ill health. Waist circumference (WC) measurement in adults can quantify abdominally-accumulated fat and is used as a clinical measure for CVD risk (Lean et al. 1995). Other measures such as the WC:height ratio (WHtR) and waist:hip ratio can also be used to indicate abdominal obesity and its related risk (Ashwell et al. 1996).

There has been an assumption that intra-abdominal (or visceral) fat accumulation is a phenomenon associated mainly with adulthood and hence adult risk for CVD. Thus, for a long time visceral fat remained unmeasured in the childhood population. Furthermore, the technology available at the time for quantifying visceral fat (computerised tomography) was thought to be prohibitive to its use in children because of the radiation risk. As a result, for some time the metabolic risk of intra-abdominal adipose tissue accumulation in children was overlooked and so the use of WC as a measure of body fat distribution in children was ignored. De Ridder et al. (1992) and Fox et al. (1993) were among the first investigators to examine intra-abdominal fat deposition in children. Both studies used nuclear magnetic resonance imaging in 11-year-old children and late pubertal girls. Essentially, in both studies it was found that whilst intra-abdominal or visceral fat is present in children, its amount is highly variable between individuals and the percentage of cross-sectional area taken up by visceral fat is less than that found in normal-weight adults. In addition, in these children subcutaneous abdominal adipose tissue was found to be predominant compared with intra-abdominal adipose tissue. However, a proportion of the children were found to have intra-abdominal:subcutaneous abdominal fat values that have been associated with higher health risks in obese adults. These findings would suggest that the partitioning of dietary energy (as triacylglycerol) between the intra-abdominal depot and subcutaneous depot in childhood is a regulated process that is incompletely understood. The process by which excess fat can accumulate intra-abdominally in children must relate, in part, to the biology of adipose tissue growth and different physiological mechanisms must exist for the acquisition of subcutaneous and intra-abdominal adipose tissue mass (Huang et al. 2001). As a measure of intraabdominal fat deposition in these children, waist to hip ratio was not found to be a useful marker, whereas WC alone was found to be a good predictor of abdominal fatness. It should be noted that these observations were conducted before the current obesity epidemic and, given the increases seen in WC in UK children (see p. 388), a repeat of those earlier magnetic resonance imaging studies may prove more illuminating. Later research using dualenergy X-ray absorptiometry has confirmed that the strongest correlate of fat distribution in children and adolescents is WC and it is also the correlate least affected by gender, ethnicity, age and overall fatness (Daniels et al. 2000; Taylor et al. 2000).

Given the association between excess abdominal fat in adults and morbidity, is the same true for children? It is indeed the case, as a number of studies have demonstrated. In a group of obese children aged 10-15 years intraabdominal adipose tissue mass was shown to be positively and significantly $(P<0 \cdot 04)$ related to both total cholesterol and LDL-cholesterol, and triacylglycerol levels (Brambilla et al. 1994). A separate study in obese adolescent girls has shown that cardiovascular risk factors including plasma triacylglycerol and HDL-cholesterol concentrations and systolic and diastolic blood pressure are directly related to the amount of intra-abdominal fat (Caprio et al. 1996). Similar findings have also been reported for obese children aged 7-11 years (Owens et al. 1998). In relation to insulin sensitivity and risk for type 2 diabetes mellitus, intraabdominal adipose tissue (assessed by magnetic resonance imaging) has been shown to be highly correlated with basal insulin secretion, glucose-stimulated insulin secretion and insulin sensitivity in obese adolescent girls (Caprio et al. 1995). Studies reviewed by Goran \& Gower (1999) have shown the clinical relevance of intra-abdominal adipose tissue in children and adolescents, including its effects on dyslipidaemia and glucose tolerance.

Whilst these measurements of intra-abdominal adipose tissue in children by imaging techniques correlate with risk for CVD and MS, it must be remembered that the intraabdominal adipose mass is only one component of the $\mathrm{WC}$, and $\mathrm{WC}$ measurement in children relates to both subcutaneous abdominal fat and intra-abdominal fat. Thus, it is also important to determine whether WC rather than intra-abdominal fat relates to CVD risk in children. A study of a group of 12-14-year-old obese children (Flodmark et al. 1994) has shown that after adjusting for puberty and gender WC is significantly correlated with HDL-cholesterol $(P<0 \cdot 05)$ and plasma triacylglycerol $(P<0 \cdot 01)$ levels, indicating that for this group of obese children, abdominal obesity is related to an adverse blood lipid profile and that WC measurement is a convenient and informative indicator of obesity-related metabolic alterations. Further to these observations, the Bogalusa Heart Study (Freedman et al. 1999) has examined the relationship between WC and measures of lipid and insulin concentrations in 5-17-year-olds. Again, it was found that, independently of age, height, weight, gender and ethnicity, 
increasing $\mathrm{WC}$ is associated with increasing fasting insulin concentration (indicative of insulin resistance) together with adverse concentrations of plasma triacylglycerols and LDL- and HDL-cholesterol. From the latter study it was further concluded that information on body fat distribution, particularly WC measurement, may help to identify those children who are likely to have adverse blood concentrations of insulin and lipids. More recently, an important finding from the Avon Longitudinal Study of Parents and Children (ALSPAC) project (see p. 389) has demonstrated raised plasma cholesterol and triacylglycerol concentrations in preschool children with the highest WC (Cowin et al. 2000).

Evidence for a relationship between WC and blood pressure in children is not as abundant, although using data from ALSPAC an increase has been observed in systolic blood pressure in 4- and 5-year-olds with increasing WC (HD McCarthy, KV Jarrett, PM Emmett, I Rogers and the ALSPAC Study Team, unpublished results). In prepubertal children systolic and diastolic blood pressure, as well as apoA1:apoB, total cholesterol and HDL-cholesterol have been shown to be significantly associated with WC, independently of age, gender and BMI $(P<0.01$; Maffeis et al. 2001). Furthermore, children identified with a WC in the top $10 \%$ of the age- and gender-related distribution are more likely to have multiple risk factors than children with a WC in the remaining $90 \%$ of the WC distribution. In pubertal children positive relationships between systolic and diastolic blood pressure and trunk fat (determined by both WC measurement and dual-energy X-ray absorptiometry and adjusted for total fat) have been found in boys but not in girls (He et al. 2002a). Thus, a broad range of evidence in children of all ages suggests that WC is strongly associated with obesity-related morbidity and is a useful measurement to identify those children most at risk, and one which is easy to undertake with an acceptable extent of reproducibility (see p. 390).

\section{Waist circumference percentile charts}

Given the findings of the research into intra-abdominal fat accumulation in children, its association with metabolic risk factors and the ability of WC to predict abdominal fatness, WC centile charts should prove to be a useful addition or alternative to BMI centile charts in the clinical assessment of childhood obesity. Compared with BMI, WC would better identify children with high abdominal fatness and hence risk for MS. This premise is especially true given the known limitations of BMI and BMI centile charts in children for identifying those who may be at risk for the MS. Up until 2001, there had been no obesity-related reference data for WC in UK children, but WC centile charts had been developed for the Italian (aged 6-14 years; Zannolli \& Morgese, 1996) and Spanish (aged 6-15 years; Moreno et al. 1999) paediatric populations. Waist:hip ratio centiles had also been developed for Cuban children and adolescents (Martinez et al. 1994). For equivalent UK charts it was essential that historical data were utilised and collected before the emergence of the current obesity epidemic. If contemporary data had been used, then comparison with the UK references for height, weight and BMI would be difficult (Cole et al. 1995). One key issue in the development of the WC centile chart and the use of WC measurement in paediatric obesity research is that there is no universal agreement on the definition of the WC landmark. Most research groups have taken the WC as being mid-way between the 10th rib and the top of the iliac crest (for example, see Freedman et al. 1999; Moreno et al. 1999). Others, such as those who developed the Italian charts, have measured WC at the level of the umbilicus (Zannolli \& Morgese, 1996). This disparity makes comparisons between populations difficult.

Data used for the development of the UK WC centile charts were collected in 1977 for boys and 1987 for girls and the measurement site was the midpoint between the 10th rib and the top of the iliac crest (British Standards Institute, 1990). Using the LMS curve-fitting software developed by Cole and colleagues (Cole, 1990), genderspecific and age-related smoothed centile charts have been constructed (McCarthy et al. 2001). In this dataset there is an age-related increase in mean WC up to age 17 years. Gender differences are evident from age 9 years onwards, with boys having the greater mean WC at each age; the difference in mean WC between boys and girls at age 17 years is $6.3 \mathrm{~cm}$. At present, the published WC centile charts cover the age-range between 3 and 17 years, and include the standard nine centile lines, with a channel width of 0.66 SD score. The 91st and 98th centiles are used to define overweight and obese, in line with the UK BMI charts.

Since the development of WC centile charts for UK children, other nations have produced similar charts, including Cyprus (ages 6-17 years; Savva et al. 2001), USA (ages 2-18 years; Fernandez et al. 2004), Canada (ages 11-18 years; Katzmarzyk, 2004), Australia (ages 7-15 years, Eisenmann, 2005), The Netherlands (ages birth to 21 years; Fredriks et al. 2005) and Mexico (ages 6-10 years; Gomez-Diaz et al. 2005). However, there is variation between these studies in the landmark used to define the waist, again leading to potential difficulties when attempting to make cross-cultural comparisons. Furthermore, most of the WC data were collected from contemporary children and in countries with known increased prevalences of overweight and obesity.

When BMI-WC relationships in children and adolescents are examined, a strong positive relationship between these two variables exists. However WC can vary greatly for a given BMI at a particular age. As a result, this relationship can give an insight into how combining age-related BMI and WC measurements could improve the identification of those children most at risk of MS, and conversely how it could assist in avoiding the incorrect classification of some children. Table 1 illustrates this issue in four boys of approximately similar age, and the BMI-WC relationships highlighted can be demonstrated across all ages and in both genders.

As two separate measures of fatness BMI and WC interact in a complex fashion, especially in childhood, and are both influenced by age, gender and pubertal stage. In a recent cross-sectional study in 474 healthy adolescents aged 17 years (Neovius et al. 2005) both BMI and WC 
Table 1. Combining age-related BMI and waist circumference (WC) measurements could assist in avoiding the incorrect classification of some children, as illustrated for four boys of similar age*

\begin{tabular}{lccccc}
\hline Subject & $\begin{array}{c}\text { Age } \\
\text { (years) }\end{array}$ & $\begin{array}{c}\mathrm{BMI} \\
\left(\mathrm{kg} / \mathrm{m}^{2}\right)\end{array}$ & $\begin{array}{c}\text { WC } \\
(\mathrm{cm})\end{array}$ & $\begin{array}{c}\text { BMI } \\
\text { percentile }\end{array}$ & $\begin{array}{c}\text { WC } \\
\text { percentile }\end{array}$ \\
\hline A & $7 \cdot 7$ & $15 \cdot 2$ & 48 & Approx 50th & $<9$ th \\
B & $7 \cdot 5$ & $15 \cdot 3$ & 65 & Approx 50th & $\begin{array}{c}>98 \text { th } \\
\text { C }\end{array}$ \\
D & $7 \cdot 1$ & $19 \cdot 1$ & 53 & $>91$ st & $\begin{array}{c}\text { Approx 50th } \\
>99.6 \text { th }\end{array}$ \\
\hline
\end{tabular}

Approx, approximately.

*Child A can be considered a reference child with an average BMI for age and gender. Child B, based on BMI would also be considered average for age. However, when WC is taken into account, this child would be classified as obese. The latter is an example of where there is not excess body mass, but excess central body fat accumulation (furthermore, it is likely that this child would be shorter than child A). Child $\mathrm{C}$ would be considered overweight based on his BMI, but his WC is average. This example could be a case where the child is more muscular (and possibly taller, leading to a greater fat-free mass) for his age. Finally, child D is considered obese based on his BMI and obese based on his WC

have been shown to perform well as diagnostic tests for fatness (air-displacement plethysmography was used as the reference method and diagnostic accuracy was evaluated through receiver operating characteristics). However, as measures of risk for obesity-related morbidity, age- and gender-related BMI and WC can lead to different interpretations. As a result, it may be more useful in clinical practice (and possibly in epidemiological studies) to perform both measurements and to make an evaluation on the child based on the combined observations. Indeed, such a recommendation has been supported by findings in children for whom outcome measures of HDL-cholesterol level, triacylglycerol level, high glucose level, high insulin level and high blood pressure were predicted from agespecific BMI and WC values (Katzmarzyk et al. 2004; Janssen et al. 2005). From these studies the authors have concluded that a combination of BMI and WC should be recommended for use clinically to predict risk factor clustering and elevated health risk among children and adolescents.

\section{Secular changes in abdominal fatness in children}

Reference data for WC and hence abdominal fatness in UK children exists. Thus, in view of the escalation in childhood overweight and obesity, it was important to determine whether abdominal fatness has increased in British children, thus increasing the numbers at risk for the metabolic consequences of abdominal obesity and the MS. This issue was resolved by comparing the WC reference data (McCarthy et al. 2001) with that collected 10 and 20 years later for 11-16-year-old children participating in the National Diet and Nutrition Survey (Gregory \& Lowe, 2000). This survey was the first contemporary nationallyrepresentative children's survey in which WC measurements had been collected. Fortunately, the landmark used for WC measurement was the same as that for the earlier survey. In the analysis (McCarthy et al. 2003) WC was expressed as a standard deviation score, using the first survey (British Standards Institute, 1990) as the reference.
Changes in BMI were analysed in the same way but using the UK data as the reference (Cole et al. 1995). Overweight and obesity were defined as measurements $>91 \mathrm{st}$ and 98th centile respectively. The key finding from this study is the sharp increase in WC over the 10-year period in girls $(6.2 \mathrm{~cm}, 1.02 \mathrm{SD}$ score; $P<0.0001)$ and over the 20 -year period in boys $(6.9 \mathrm{~cm}, 0.84$ sD score; $P<0.0001)$. In centile terms, the increase was found to be greater for girls than for boys. For BMI, the extent of the increase was smaller and was similar for boys and girls (mean 1.5 and 1.6 BMI units respectively, or 0.47 and $0.53 \mathrm{SD}$ score; $P<0 \cdot 0001)$. In the National Diet and Nutrition Survey (Gregory \& Lowe, 2000) sample WC was found to exceed the 91 st centile in $28 \%$ of boys and $38 \%$ of girls, with $14 \%$ and $17 \%$ of boys and girls respectively exceeding the 98th centile $(P<0 \cdot 0001)$. By comparison, for BMI $17 \%$ of boys and $21 \%$ of girls were found to exceed the $91 \mathrm{st}$ centile in the National Diet and Nutrition Survey (Gregory \& Lowe, 2000) sample, with the corresponding rates for the 98th centile being $10 \%$ for boys and $8 \%$ for girls. These findings clearly demonstrate that increases in central fatness over the past 10-20 years (measured by WC) have exceeded increases in overall fatness (measured by the $\mathrm{BMI}$ ) and that BMI is a poor proxy for central fatness. These findings also indicate that obesity prevalence has been systematically underestimated by measurements based on height and weight. As indicated earlier, BMI measures the sum of fat mass and fat-free mass (Maynard et al. 2001; Wells et al. 2002), and it is impossible to know the contribution of each compartment to these increases in BMI in this study. The increase in WC is unlikely to be entirely a result of increases in visceral adipose tissue, and probably reflects subcutaneous and hence total fatness. Taken together, these findings suggest that body composition (and hence body shape) has changed over this period of time, with the increase in (central) fat mass being obscured by decreases in fat-free (and hence probably skeletal muscle) mass. Whether this possible skeletal muscle issue is related to decreases in physical activity levels is unclear at this time. It is known that in obese adolescents excess fat accumulates predominantly in the upper body region rather than in the peripheral region (Brambilla et al. 1994; Moreno et al. 1998). These findings have important implications for risk of MS, given the fact that children in the upper distribution of the WC values have a more atherogenic blood lipid profile and raised fasting insulin concentrations. These secular increases in $\mathrm{WC}$ and abdominal fatness in adolescents have also been demonstrated outside the UK, but over a shorter period of time, indicating the reproducibility of this phenomenon in other populations (Moreno et al. 2005). Also, an earlier study of Spanish children (Moreno et al. 2001b) has shown that between 1980 and 1995 there was a shift towards a central distribution of fat patterning in children as young as 6 years of age. These observations were based on ratios of skinfold thicknesses at the periphery and trunk and were independent of trends in BMI. Furthermore, conversion of these children's skinfold thickness measurements into predicted percentage body fatness indicates a secular increase in total percentage body fat of between 2.5 and $6.0 \%$ that is greater than the increase in BMI, again suggesting a 
change in body composition over the 15-year period (Moreno et al. 2001a).

Following on from the novel findings in adolescents (McCarthy et al. 2003), the next question to be asked was whether these body fatness findings were present in younger children. This question was answered using data from the ALSPAC study. ALSPAC is a longitudinal cohort study being conducted in the West of England, which was initiated in the early 1990s and comprises approximately 14000 children (Golding et al. 2001). A subset of these children, comprising approximately 1000 children, has been studied in more detail (known as Children in Focus). WC and BMI between the ages of 2 and 5 years were compared with values for similar-aged children measured in 1987. The essential finding of this study is a significantly greater mean WC in the ALSPAC children at equivalent ages compared with those measured in the earlier study $(P<0 \cdot 05$; McCarthy et al. 2005). Whilst mean BMI was also found to be higher in the contemporary ALSPAC cohort, the proportional increase in WC was again greater than that for BMI. These findings mirror those in the older children, suggesting a greater rate of increase in abdominal fatness than in general fatness, and the occurrence of excess central fat deposition at a very young age. Again, this study demonstrates the shortcomings of BMI measurement, indicating that it can mask the true obesity-related risk in young children.

Longitudinal studies of both total fatness and abdominal fatness in children are scarce. The Nepean study (Garnett et al. 2005), which has examined both factors in detail between 7-8 years of age and 12-13 years of age, has found an increase of 0.74 for the mean WC SD score, but an increase 0.18 for BMI SD score. These findings suggest a greater rate of increase in abdominal fatness than in overall fatness in this contemporary cohort of children.

\section{Abdominal fatness, ethnicity and health risk}

The findings discussed so far have related almost exclusively to Caucasian children. However, the prevalence of overweight and obesity and its health consequences can be greater for children from other ethnic groups, especially those from south Asian and African and Caribbean backgrounds. A recent UK study (Saxena et al. 2004) has demonstrated that British Afro-Caribbean and Pakistani girls have an increased risk of being obese, while Indian and Pakistani boys have an increased risk of being overweight. These findings suggest that these individuals may be at a greater risk of obesity-related morbidity. Studies in the USA (Goran et al. 1997; He et al. 2002b) have demonstrated ethnic differences in fat distribution among Asian, African-American and Caucasian prepubertal children. Generally, the relative distribution of adipose tissue in the intra-abdominal region compared with the subcutaneous abdominal region is significantly lower in children from African-American backgrounds compared with Caucasian children. The relationship between intraabdominal fat and insulin response in African-American children appears to be highly complex (Gower et al. 1998), although more recent findings in this ethnic group (Lee et al. 2006) have shown that WC is able to predict insulin resistance independently of BMI. The authors further suggest that the prediction of health risks associated with obesity is improved by including WC measurement alongside BMI measurement. They also emphasise the importance of including WC measurement routinely in the assessment of childhood obesity in order to identify those children at increased metabolic risk because of excess abdominal fat. Although data is less abundant that that for Caucasian children, nevertheless the findings generally concur, in that a more central distribution of fat profoundly affects CVD risk factor levels, including HDL, LDL, triacylglycerol levels and systolic and diastolic blood pressure in black boys (Morrison et al. 1999a) and black girls (Morrison et al. 1999b).

In relation to insulin resistance and risk for type 2 diabetes in children of south Asian background, recent findings from the UK (Ehtisham et al. 2005) have demonstrated that south Asian children are less insulin sensitive than white Europeans and have significantly more body fat, with a greater central fat distribution $(P<0.005)$. It was concluded that children from south Asian backgrounds are fourteen times more likely that white European children to develop type 2 diabetes. Further work is required to examine the development of central body fat accumulation in UK children from other ethnic groups, especially those from a south Asian background and African and Caribbean backgrounds. However, British south Asian children as young as 8 years of age have been shown to have higher fasting and glucose-stimulated insulin concentrations and higher triacylglycerol levels, which may reflect an increased sensitivity to adiposity (Whincup et al. 2002). Although not observed in the latter study, recent findings have shown that a more truncal distribution of fat is present at birth and in early childhood in south Indian children (Krishnaveni et al. 2005) and that this pattern of fatness may be the forerunner of a diabetogenic adult phenotype.

\section{Waist circumference alone or in combination with height?}

The evidence thus far indicates that $\mathrm{WC}$ can provide vital information in children in relation to measurement of abdominal fatness and risk for obesity-related ill health. One matter of concern, however, is the influence of stature on WC in both children and adults. There is a strong positive correlation between height and WC throughout growth, throughout childhood and into adulthood, although the precise influence of height on WC remains quantitatively unclear. It has been suggested that a measure of WC in combination with height may partly correct for the effect of height on WC. Thus, WHtR has been proposed as a simple indicator of excess abdominal fat accumulation, with a cut-off or boundary value of WHtR $\geq 0.50$ defining those with excess abdominal fatness (Ashwell et al. 1996). This measure has been proposed to be equally appropriate for use in adults and children, in both boys and girls and at all ages $>5$ years. Indeed, several studies have demonstrated the WHtR to be superior in its ability to predict CVD risk factors compared with BMI or percentage body fat (Savva et al. 2000; Hara et al. 2002; Kahn et al. 2005). A recent examination of WHtR in British children 
(McCarthy \& Ashwell, 2006) has shown that the percentage of children with a WHtR above the boundary value of 0.50 has increased in recent years (boys 17 and girls 12 v. 5 and 1.5 respectively $10-20$ years earlier).

Too many measures of central obesity in children could be confusing, but the concept of WHtR may be one that is easily grasped by the public, with a simple public health message to 'keep you waist circumference to less than half your height'. Additional work in this area should help to clarify the 0.50 boundary value and the usefulness of this ratio.

\section{Waist circumference and the metabolic syndrome in children}

As stated earlier, the MS is one of the most important public health issues affecting future generations around the world. In order to be able to readily identify those children who are most at risk of developing this disorder a simple and effective screening tool is required, and the WC appears to best fit the requirements of such a tool. While it is generally agreed that obesity is the predominant correlate of risk for MS among the young (Goodman et al. 2005), an increasing number of studies are showing that $\mathrm{WC}$ is the best measure for identifying children with insulin resistance and hypertriacylglycerolaemia, and hence those most at risk for MS (Moreno et al. 2002; Hirschler et al. 2005; Esmaillzadeh et al. 2006). WC has been found to perform better than BMI in this context, and these studies have recommended that WC should be used in paediatric clinical settings. Furthermore, when determining the prevalence of MS in prepubertal children, the classification of MS in children depends strongly on whether hyperinsulinaemia is central to the MS classification (Golley et al. 2006). The authors have concluded that there is a need for the establishment of normal insulin ranges in childhood and adolescence and a consistent definition of MS.

\section{Standardisation of waist circumference}

WC now appears to be fundamental in determining risk of MS and related disorders in both childhood and adulthood. There is, therefore, an important need for WC to be measured routinely in the clinical setting, and in epidemiological research in which obesity is a component of predictive or outcome measures. At the same time, there is an urgent need for a consensus on the definition of the WC measurement site (Wang, 2006). In adults WC measurement certainly differs, depending on the chosen landmark and gender, and there is likely to be a similar difference in children (Wang et al. 2003; Bigaard et al. 2005). Furthermore, whilst WC can be considered a simple measurement technique, this very characteristic can result in erroneous measurements. There is a need for health professionals to become proficient in WC measurement through appropriate training, practice and experience. With increasing experience, measurement error can be reduced (Ulijaszek \& Kerr, 1999) to an acceptable extent, thus allowing comparison between centres to be more reliable and valid, and for individual children to be confidently assessed in the clinical situation.

\section{Conclusions}

Research has shown that abdominal fatness is as important in children as it is in adults. Excess abdominal fatness in children results in metabolic alterations associated with features of the MS and hence risk for CVD in later life. Its measurement can add more information to that provided by BMI measurement in the paediatric clinical setting, and WC centile charts are available for clinical use in the UK. It is now time that all health professionals working in the field of childhood obesity should routinely perform WC measurement as part of a clinical assessment. Further research should demonstrate whether a WC measurement alone will be sufficient to identify those children at greatest risk for obesity-related ill health and the need for weight management.

\section{References}

Ashwell MA, LeJeune SRE \& McPherson B (1996) Ratio of waist circumference to height may be better indicator of need for weight management. British Medical Journal 312, 377.

Bigaard J, Spanggaard I, Lykke Thomsen B, Overvad K \& Tjonneland A (2005) Self-reported and technician measured waist circumferences differ in middle-aged men and women. Journal of Nutrition 135, 2263-2270.

Brambilla P, Manzoni P, Sironi S, Simone P, Del Maschio A, di Natale B \& Chiumello G (1994) Peripheral and abdominal adiposity in childhood obesity. International Journal of Obesity 18, 795-800.

British Standards Institute (1990) Body Measurements of Boys and Girls from Birth up to 16.9 Years, BS7321. London: British Standards Institute.

Bundred P, Kitchiner D \& Buchan I (2001) Prevalence of overweight and obese children between 1989 and 1998: population based series of cross sectional studies. British Medical Journal 322, 1-4.

Caprio S, Hyman LD, Limb, C, McCarthy S, Lange R, Sherwin RS, Shulman G \& Tamborlane WV (1995) Central adiposity and its metabolic correlates in obese adolescent girls. American Journal of Physiology 269, E118-E126.

Caprio S, Hyman LD, McCarthy S, Lange R, Bronson M \& Tamborlane WV (1996) Fat distribution and cardiovascular risk factors in obese adolescent girls: importance of the intraabdominal fat depot. American Journal of Clinical Nutrition 64, 12-17.

Chinn S \& Rona R (2001) Prevalence and trends in overweight and obesity in three cross-sectional studies of British children, 1974-94. British Medical Journal 322, 24-25.

Cole TJ (1990) The LMS method for constructing normalized growth standards. European Journal of Clinical Nutrition 44, 45-60.

Cole TJ, Bellizzi C, Flegal KM \& Dietz WH (2000) Establishing a standard definition for child overweight and obesity worldwide: international survey. British Medical Journal 320, 12401253.

Cole TJ, Freeman JV \& Preece MA (1995) Body Mass Index reference curves for the UK, 1990. Archives of Disease in Childhood 73, 25-29.

Cowin I, Emmett P \& the ALSPAC Study Team (2000) Cholesterol and triglyceride concentrations, birthweight and central 
obesity in pre-school children. International Journal of Obesity 24, 330-339.

Daniels SR, Khoury PR \& Morrison JA (2000) Utility of different measures of body fat distribution in children and adolescents. American Journal of Epidemiology 152, 1179-1184.

de Ridder CM, De Boer RW, Seidell JC, Nieuwenhoff CM, Jeneson JA, Bakker CJ, Zonderland ML \& Erich WB (1992) Body fat distribution in pubertal girls quantified by magnetic resonance imaging. International Journal of Obesity 16, 443-449.

Dietz WH \& Bellizzi MC (1999) Introduction: the use of body mass index to assess obesity in children. American Journal of Clinical Nutrition 70, 123-125.

Ehtisham S, Crabtree N, Clark P, Shaw N \& Barrett T (2005) Ethnic differences in insulin resistance and body composition in United Kingdom adolescents. Journal of Clinical Endocrinology and Metabolism 90, 3963-3969.

Eisenmann JC (2005) Waist circumference percentiles for 7- to 15-year old Australian children. Acta Paediatrica 94, 11821185.

Ellis KJ, Abrams SA \& Wong WW (1999) Monitoring childhood obesity: Assessment of the weight/height ${ }^{(2)}$ index. American Journal of Epidemiology 150, 939-946.

Esmaillzadeh A, Mirmiran P \& Azizi F (2006) Clustering of metabolic abnormalities in adolescents with the hypertriglyceridemic waist phenotype. American Journal of Clinical Nutrition 83, 36-46.

Fernandez JR, Redden DT, Pietrobelli A \& Allison DB (2004) Waist circumference percentiles in nationally representative samples of African-American, European-American and Mexican-American children and adolescents. Journal of Pediatrics 145, 439-444.

Flodmark CE, Sveger T \& Nilsson-Ehle P (1994) Waist measurement correlates to a potentially atherogenic lipoprotein profile in obese 12-14 year old children. Acta Paediatrica 83, 941-945.

Fox K, Peters D, Armstrong N, Sharpe P \& Bell M (1993) Abdominal fat deposition in $11 \mathrm{y}$ old children. International Journal of Obesity 17, 11-16.

Fredriks AM, van Buuren S, Fekkes M, Verloove-Vanhorick SP \& Wit JM (2005) Are age references for waist circumference, hip circumference and waist-hip ratio in Dutch children useful for clinical practice? European Journal of Paediatrics 164, 216-222.

Freedman DS, Serdula MK, Srinivasan SR \& Berenson GS (1999) Relation of circumferences and skinfold thicknesses to lipid and insulin concentrations in children and adolescents: the Bogalusa Heart Study. American Journal of Clinical Nutrition 69, 308-317.

Garnett SP, Cowell CT, Baur LA, Shrewsbury VA, Chan A, Crawford D, Salmon J, Campbell K \& Boulton TJ (2005) Increasing central adiposity: the Nepean longitudinal study of young people aged 7-8 to 12-13 y. International Journal of Obesity 29, 1353-1360.

Golding J, Pembrey M, Jones R \& ALSPAC Study Team (2001) ALSPAC - The Avon Longitudinal Study of Parents and Children. I. Study methodology. Paediatric and Perinatal Epidemiology 15, 74-87.

Golley RK, Magarey AM, Steinbeck KS, Baur LA \& Daniels LA (2006) Comparison of metabolic syndrome prevalence using six different definitions in overweight pre-pubertal children enrolled in a weight management study. International Journal of Obesity 30, 853-860.

Gomez-Diaz RA, Martinez-Harnandez AJ, Aquilar-Salinas CA, Violante R, Alarcon ML, Villarruel MJ, Rodarte NW \& Solorzano-Santos F (2005) Percentile distribution of the waist circumference among Mexican pre-adolescents of a primary school in Mexico City. Diabetes Obesity and Metabolism 7, 716-721.

Goodman E, Dolan LM, Morrison JA \& Daniels SR (2005) Factor analysis of clustered cardiovascular risks in adolescence - obesity is the predominant correlate among youth. Circulation 111, 1970-1977.

Goran MI, Nagy TR, Treuth MS, Trowbridge C \& Dezenberg C (1997) Visceral fat in white and African American pre-pubertal children. American Journal of Clinical Nutrition 65, 17031708 .

Goran MI \& Gower BA (1999) Relation between visceral fat and disease risk in children and adolescents. American Journal of Clinical Nutrition 70, Suppl., 149S-156S.

Gower BA, Nagy TR, Trowbridge CA, Dezenberg C \& Goran MI (1998) Fat distribution and insulin response in pre-pubertal African American and white children. American Journal of Clinical Nutrition 67, 821-827.

Gregory J \& Lowe S (2000) National Diet and Nutrition Survey, Young People Aged 4 to 18 Years. London: The Stationery Office.

Hara M, Saito E, Iwata F, Okada T \& Harada K (2002) Waistto-height ratio is the best predictor of cardiovascular disease risk factors in Japanese schoolchildren. Journal of Atherosclerosis and Thrombosis 9, 127-132.

He Q, Horlick M, Fedun B, Wang J, Pierson R, Heshka S \& Gallagher D (2002a) Trunk fat and blood pressure in children through puberty. Circulation 105, 1093-1098.

He Q, Horlick M, Thornton J, Wang J, Pierson RN, Heshka S \& Gallagher D (2002b) Sex and race differences in fat distribution among Asian, African-American and Caucasian pre-pubertal children. Journal of Clinical Endocrinology and Metabolism 87, 2164-2170.

Hirschler V, Aranda C, Calcagno MD, Maccalini G \& Jadzinsky M (2005) Can waist circumference identify children with the metabolic syndrome? Archives of Pediatric and Adolescent Medicine 159, 740-744.

Huang TTK, Johnson MS, Figueroa-Colon R, Dwyer JH \& Goran MI (2001) Growth of visceral fat, subcutaneous abdominal fat and total body fat in children. Obesity Research 9, 283-289.

Janssen I, Katzmarzyk PT, Srinivasan SR, Chen W, Malina RM, Bouchard C \& Berenson GS (2005) Combined influence of body mass index and waist circumference on coronary artery disease risk factors among children and adolescents. Pediatrics 115, 1623-1630.

Kahn HS, Imperatore G \& Cheng YJ (2005) A population-based comparison of BMI percentiles and waist-to-height ratio for identifying cardiovascular risk in youth. Journal of Pediatrics 146, 482-488.

Katzmarzyk PT (2004) Waist circumference percentiles for Canadian youth aged 11-18 y of age. European Journal of Clinical Nutrition 58, 1011-1015.

Katzmarzyk PT, Srinivasan SR, Chen W, Malina RM, Bouchard C \& Berenson GS (2004) Body mass index, waist circumference and clustering of cardiovascular disease risk factors in a biracial sample of children and adolescents. Pediatrics 114, 198-205.

Kopelman PG \& Albon L (1997) Obesity, non-insulin-dependent diabetes mellitus and the metabolic syndrome. British Medical Bulletin 53, 322-340.

Krishnaveni GC, Hill JC, Veena SR, Leary SD, Saperia J, Chachyarnma KJ, Karat SC \& Fall CHD (2005) Truncal adiposity is present at birth and in early childhood in south Indian children. Indian Pediatrics 42, 527-538.

Lean ME, Has TS \& Morrison CE (1995) Waist circumference as a measure for indicating need for weight management. British Medical Journal 311, 158-161. 
Lee S, Bacha F, Gungor N \& Arslanian SA (2006) Waist circumference is an independent predictor of insulin resistance in black and white youths. Journal of Paediatrics 148, 188-194.

Lobstein T, Baur L \& Uauy R for the IASO International Obesity Task Force (2004) Obesity in children and young people: a crisis in public health. Obesity Reviews 5, Suppl. 1, 4-85.

Lobstein TJ, James WPT \& Cole TJ (2003) Increasing levels of excess weight among children in England. International Journal of Obesity 27, 1136-1138.

McCarthy HD \& Ashwell M (2006) A study of central fatness using waist: height ratios in UK children and adolescents over two decades supports the simple message - 'keep your waist circumference to less than half your height'. International Journal of Obesity 30, 988-992.

McCarthy HD, Ellis SM \& Cole TJ (2003) Dramatic increases in central overweight and obesity in British children aged 11-16 year: cross-sectional surveys of waist circumference. British Medical Journal 326, 624-627.

McCarthy HD, Jarrett KV \& Crawley HF (2001) The development of waist circumference percentiles in British children aged 5.0-16.9 years. European Journal of Clinical Nutrition 55, 902-907.

McCarthy HD, Jarrett KV, Emmett PM, Rogers I \& The ALSPAC Study Team (2005) Trends in waist circumference in young British children: a comparative study. International Journal of Obesity 29, 157-162.

Maffeis C, Pietrobelli A, Grezzani A, Provera S \& Tato L (2001) Waist circumference and cardiovascular risk factors in prepubertal children. Obesity Research 9, 179-187.

Martinez E, Devesa M, Bacallao J \& Amador M (1994) Percentiles of the waist-hip ratio in Cuban scholars aged 4.5-20.5 years. International Journal of Obesity 18, 557-560.

Maynard LM, Wisemandle W, Roche AF, Chumlea WC, Guo SS \& Siervogel RM (2001) Childhood body composition in relation to body mass index. Pediatrics 107, 344-350.

Moreno LA, Fleta J, Mur L, Rodriguez G, Sarria A \& Bueno M (1999) Waist circumference values in Spanish children gender related differences. European Journal of Clinical Nutrition 53, 429-433.

Moreno LA, Fleta J, Mur L, Sarria A \& Bueno M (1998) Fat distribution in obese and non-obese children and adolescents. Journal of Paediatric Gastroenterology and Nutrition 27, 176-180.

Moreno LA, Fleta J, Sarria A, Rodriguez G \& Bueno M (2001a) Secular increases in body fat percentage in male children of Zaragoza, Spain, 1980-1995. Preventive Medicine 33, 357-363.

Moreno LA, Fleta J, Sarria A, Rodriguez G, Gil C \& Bueno M (2001b) Secular changes in body fat patterning in children and adolescents of Zaragoza (Spain), 1980-1995. International Journal of Obesity 25, 1656-1660.

Moreno LA, Pineda I, Rodriguez G, Fleta J, Sarria A \& Bueno M (2002) Waist circumference for the screening of the metabolic syndrome in children. Acta Paediatrica 91, 1307-1312.

Moreno LA, Sarria A, Fleta J, Marcos A \& Bueno M (2005) Secular trends in waist circumference in Spanish adolescents, 1995 to 2000-02. Archives of Disease in Childhood 90, 818-819.

Moreno LA, Sarria A, Fleta J, Rodriguez G \& Bueno M (2000) Trends in body mass index and overweight prevalence among children and adolescents in the region of Aragon (Spain) from 1985 to 1995. International Journal of Obesity 24, 925-931.

Morrison JA, Barton BA, Biro FM, Daniels SR \& Sprecher DL (1999a) Overweight, fat patterning and cardiovascular disease risk factors in black and white boys. Journal of Paediatrics 135, 451-457.

Morrison JA, Sprecher DL, Barton BA, Waclawiw MA \& Daniels SR (1999b) Overweight, fat patterning and cardiovascular disease risk factors in black and white girls: The National Heart, Lung and Blood Institute Growth and Health Study. Journal of Paediatrics 135, 458-464.

Must A (1996) Morbidity and mortality associated with elevated body weight in children and adolescents. American Journal of Clinical Nutrition 63, Suppl., 445S-447S.

National Center for Health Statistics (2000) Pediatric growth charts. www.cdc.gov/growthcharts

Neovius M, Linne Y \& Rossner S (2005) BMI, waistcircumference and waist-hip-ratio as diagnostic tests for fatness in adolescents. International Journal of Obesity $\mathbf{2 9}$, $163-169$

Owens S, Gutin B, Ferguson M, Allison J, Karp W \& Le NA (1998) Visceral adipose tissue and cardiovascular risk factors in obese children. Journal of Pediatrics 133, 41-45.

Reilly JJ, Dorosty AR, Emmett PM \& the ALSPAC Study Team (2000) Identification of the obese child: adequacy of the body mass index for clinical practice and epidemiology. International Journal of Obesity 24, 1623-1627.

Savva SC, Kourides Y, Tornaritis M, Epiphaniou-Savva M, Tafouna P \& Kafatos A (2001) Reference growth curves for Cypriot children 6 to 17 years of age. Obesity Research $\mathbf{9}$, 754-762.

Savva, SC, Tornaritis, M, Savva ME, Kourides Y, Panagi A, Silikiotou N, Georgiou C \& Kafatos A (2000) Waist circumference and waist-to-height ratio are better predictors of cardiovascular disease risk factors in children than body mass index. International Journal of Obesity 24, 1453-1458.

Saxena S, Ambler G, Cole TJ \& Majeed A (2004) Ethnic differences in overweight and obese children and young people in England: cross sectional survey. Archives of Diseases in Childhood 89, 30-36.

Sproston K \& Primatesta P (editors) (2002) Health Survey for England. London: The Stationery Office.

Taylor RW, Jones IE, Williams SM \& Goulding A (2000) Evaluation of waist circumference, waist-to-hip ratio and the conicity index as screening tools for high trunk fat mass, as measured by dual-energy X-ray absorptiometry, in children aged 3-19 years. American Journal of Clinical Nutrition 72, 490-495.

Ulijaszek SJ \& Kerr DA (1999) Anthropometric error and the assessment of nutritional status. British Journal of Nutrition $\mathbf{8 2}$, $165-177$

Wang J (2006) Standardization of waist circumference reference data. American Journal of Clinical Nutrition 83, 3-4.

Wang J, Thornton JC, Bari S, Williamson B, Gallagher D, Heymsfield SB et al. (2003) Comparisons of waist circumference measured at 4 sites. American Journal of Clinical Nutrition 77, 379-383.

Weiss R \& Caprio S (2005) The metabolic consequences of childhood obesity. Best Practice and Research Clinical Endocrinology and Metabolism 19, 405-419.

Weiss R, Dziura J, Burgert TS, Tamborlane WV, Taksali SE, Yeckel CW et al. (2004) Obesity and the metabolic syndrome in children and adolescents. New England Journal of Medicine 350, 2362-2374.

Wells JCK, Coward WA, Cole TJ \& Davies PSW (2002) The contribution of fat and fat-free tissue to body mass index in contemporary children and the reference child. International Journal of Obesity 26, 1323-1328.

Whincup PH, Gilg JA, Papacosta O, Seymour C, Miller GJ, Alberti KGMM \& Cook DG (2002) Early evidence of ethnic differences in cardiovascular risk: cross sectional comparison of British South Asian and white children. British Medical Journal 324, 1-6.

Zannolli R \& Morgese G (1996) Waist percentiles: a simple test for atherogenic disease. Acta Paediatrica 85, 1368-1369. 